\title{
Remote Experimentation Network - Yielding an Inter-University Peer-to-Peer e-Service
}

\author{
Gustavo R. Alves ${ }^{\mathrm{i}}$, José M. Ferreira ${ }^{\mathrm{ii}}$, \\ Dieter Müller iii $^{\text {ii }}$ Heinz-H Erbe ${ }^{\text {iv }}$, Nick Hine ${ }^{v}$ \\ iIPP, Porto, Portugal, gca@isep.ipp.pt \\ iiUP, Porto, Portugal,jmf@fe.up.pt \\ iii UB, Bremen, Germany, mueller@artec.uni- \\ bremen

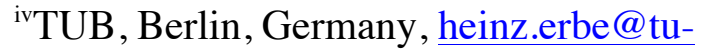 \\ berlin.de \\ 'UD, Dundee, Scotland, \\ nhine@computing.dundee.ac.uk
}

\begin{abstract}
The goal of this paper is to discuss the benefits and challenges of yielding an inter-continental network of remote laboratories supported and used by both European and Latin American Institutions of Higher Education. Since remote experimentation, understood as the ability to carry out real-world experiments through a simple web browser, is already a proven solution for the educational community as a supplement to on-site practical lab work (and in some cases, namely for distance learning courses, a replacement to that work), the purpose is not to discuss its technical, pedagogical, or economical strengths, but rather to raise and try to answer some questions about the underlying benefits and challenges of establishing a peer-to-peer network of remote labs. Ultimately, we regard such a network as a constructive mechanism to help students gain the working and social skills often valued by multinational/global companies, while also providing awareness of local cultural aspects.
\end{abstract}

\section{Introduction}

What is the motivation to remote experimentation? A brief, not complete survey on existing literature reports the following answers:

- It is a complementary educational resource that allows students to run physical experiments from any computer connected to the Internet, in addition to performing those same experiments at a local lab, as part of their normal practical work, in a given course curricula;

- Likewise, it allows teachers to better demonstrate physical concepts during a traditional lecture (i.e. a

\author{
J. B. M. Alves ${ }^{\mathrm{vi}}$, Carlos E. Pereira $^{\mathrm{vii}}$, Luciano \\ Chiang $^{\text {viii }}$, Oriel Herrera ${ }^{\text {ix }}$, Enrique Sucar ${ }^{x}$

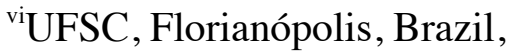 \\ jbosco@inf.ufsc.br

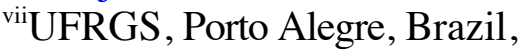 \\ cpereira@eletro.ufrgs.br \\ viiiUCC, Santiago, Chile, lchiang@ing.puc.cl

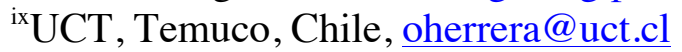 \\ 'ITESM, Cuernavaca, Mexico, \\ esucar@itesm.mx
}

theoretical presentation on a classroom), by simply connecting to the remote lab and running one or more experiments;

- It closes the gap between simulation and real-world experiments, while still using a simple PC. Interestingly enough, the concept of a virtual lab is somewhere between a simulation environment and a remote lab, as although it is a simulation (i.e. the actions are performed on a model), the context is very close to what happens in the lab. Very often the virtual lab acts as an antechamber to the remote lab, allowing the student to practice his/her skills on a safe environment and then, when confident enough, try out the same actions on real equipment and/or devices.

- It is an economic solution for distance learning courses on engineering fields that traditionally require one or more on-campus weeks for completing the practical part of the courses. Within this concept (economics) is also the possibility of accepting more students at private universities that often limit their numerus clausus according to their maximum lab capacities (a well equipped lab with technician support is often costly to any organization).

- Because real experiments are conducted through a computer interface, all accessibility problems are transferred from the lab domain to the computer domain, where a number of proven solutions are already available;

- It allows access to expensive equipment (e.g. an electron microscope) on a 24-hours, 7-days basis (not counting on maintenance periods), giving students the opportunity to use it, or otherwise they would be unable to do so;

- It allows collaborative work, although this set-up brings additional requirements: existence of 
synchronous communications tools (chat, audio- or video conference); possibility of passing the control to other users engaged on a session, or devising some sort of a collaborative scheme (e.g. one student controls equipment $\mathrm{A}$ and another student controls equipment $\mathrm{B}$, both interacting to achieve the learning objective); among others.

Perceiving the motivation is essential to answer two other important questions: what is the added value of remote experimentation and how can it be measured? The reasoning is simple: if it is possible to measure a) the educational gain obtained through remote experimentation and $b$ ) the effort made to set up or use it (here, we distinguish the supplier/client perspectives - an issue to discuss later, at this paper), then subtracting the two and comparing against the motivation aspect(s) provides an idea of the added value. If the result does not match the initial expectation(s) then a possible solution is to look into the equation and try to improve the equation terms, i.e. increase the educational value and/or reduce the effort.

The proposed solution is part of the ground that helps to understand the benefits and challenges associated with a network of remote laboratories. The rest of the paper is organized as follows: section 2 provides some more background on remote experimentation; section 3 presents a brief analysis of existing networks of remote labs and, also, why/how some universities united efforts to submit a proposal to the ALFA-II (América Latina Formación Académica) program, for sponsoring yet another network; section 4 presents the proposal itself, namely the network composition, the project goals and activities, and the consortium's past experience, current resources, and expectations; finally, section 5 highlights the points perceived by the consortium as the benefits and challenges of creating and sustaining a peer-to-peer network of remote labs. Section 6 concludes the paper.

\section{Background}

Besides the motivation aspects listed on the previous section, remote experimentation sometimes appears as a natural evolution of something previously existent. For instance, certain equipment was originally controlled by a dedicated electronic interface (e.g. in a nuclear power plant). With the widespread of computers, the dedicated interface became a computer program, and later, with the emergence of networked computers, it became possible to control that equipment from any computer connected to the same network [1, 2, 3, and 4]. This could be seen as bottom-up approach as the equipment was originally meant to be remote controlled, and then following the trend associated with adopting computer-based interfaces, and later interconnecting the computers, it became possible to remote control the same equipment (or its natural evolution) from any computer connected to the Internet. As, at the Higher Education level, there is a concern to cover case-studies based on real equipment, it immediately followed the access to those equipments in a remote experimentation scenario.

Following a top-down approach, several universities started to use computers as an educational tool, justifying the expression Computer Based Learning (CBL), now widely associated with similar expressions such as e-learning and distance learning, among others. Within engineering, soon the educational community felt the need for more powerful combinations: linking educational contents from several sources; links from text documents to modules with hands-on, namely on simulation; and finally, to real-world experiments [5]. The World Wide Web (WWW) and its associated technologies (hypertext, web browsers, etc.) provided the platform for the large-scale ${ }^{1}$ implementation of such concepts and ideas, including the free offer of educational materials to the entire engineering community [6]. On the last topic (remote experimentation), the first references to making an entire undergraduate lab available through the WWW, date back to the mid 90's. Aktan [7] claims his real-time remote-access control engineering teaching lab to be the first (on its class) undergraduate lab with complete (interactive) Internet access. Aktan also uses the expression "Second Best to Being There" (SBBT) to characterize the complementary nature of remote labs. Esche $[8,9]$ describes a more recent undergraduate lab, with a strong emphasis on pedagogical issues and enabling technologies.

Two examples of such approaches (bottom-up and top-down), relevant within the context of this paper, come from the Federal University of Rio Grande do Sul (UFRGS, Brazil) and the Faculty of Engineering of the University of Porto (FEUP, Portugal). Following on the teaching of control engineering and industrial networks, where the need for providing relevant hands-on materials to students, is particularly regarded by the surrounding industrial companies (ultimately, the employers of UFRGS graduates), some elements of the Department of Electrical Engineering set up an experiment on a closed loop of two hydraulic tank circuit controlled by FieldBus devices. This experiment is used to: a) teach concepts on control engineering (e.g. PID control, closed-loop control); and b) teach current technology on industrial networks (e.g. FieldBus). As the control devices are equipped with an Ethernet port, the interconnection to the Internet and the possibility of web-based access for setting up a remote experimentation scenario immediately followed [10]. Following a top-down approach, an R\&D group (accumulating lecture duties) of FEUP, started to develop web-based educational materials on electronic test, first on a simple form [11]

1 While in 1993 the number of web servers available around the world reached a total of 50 units, the current number is in the order of several tenths of million. 
and then using richer multimedia approaches $[12,13$, and 14] with a strong emphasis on the pedagogical aspects associated with e-learning materials [15]. Adding the possibility of performing remote hands-on sessions was the last step towards a complete web-based solution for the teaching of electronic test concepts $[16,17,18$, 19, and 20].

\section{Networked remote labs}

The WWW brought new possibilities to the educational community in terms of cooperation and collaboration in producing, sharing, linking, and updating learning materials, especially in engineering fields as quite often such activities require some knowledge of the enabling technologies (e.g. web programming tools such as Java and php, among others). For instance, a few years after the WWW inception, Cobby reported close cooperation among a number of British universities to produce web-based contents for teaching electronic engineering, under the INTERACT project [5]. This sort of cooperation scheme among universities soon followed the two approaches described in the previous section, and so the passage of isolated remote experiments (or labs) to networked remote experiments (or labs) came obviously [21, 22, 23, and 24]. Noticeably, Eikaas [23] describes the creation of a business model based on a scheme where individual experiment owners offer remote access to their laboratory facilities. The access to these facilities is offered via an independent operating company (CyberLab) - the Experiment Service Provider (ESP) that offers eCommerce services like booking, access control, invoicing, dispute resolution, quality control, customer evaluation services and a unified Lab Portal. Although Eikaas refers several cost levels, starting from free access to a limited set of the ESP services, the basic idea is somewhat conflicting with the general cooperation schemes used within academia. In fact, and concerning to remote experimentation, cooperation / collaboration can be addressed distinctly from the supplier and client perspectives. Within the solution provided by CyberLab, the client may either be an university willing to have its remote experiment (or lab) included in the ESP portal or an university willing to use one of the remote experiments made available through the portal. Further down, and within the last mentioned university, the client may actually be a teacher willing to: a) access a remote lab for a real demo within one lecture; or b) propose its use to students enrolled on his/her course. The last envisaged scenario raises additional questions if the remote experiment calls for collaborative work among the students, i.e. two or more students have to work as a group in order to complete it [25, 26, and 27]. Being one of the most valued aspects of lab practice - team work - one may argue if such a scheme could not benefit from having students from several universities (not necessarily from the same country or continent) working together to achieve a certain learning objective. In our opinion, cost figures are generally not perceived in the same way by different universities, and as such the number of potential users may diminish substantially, or be confined to students belonging to universities with no budget restrictions to acquire yet another complementary educational resource. This situation fails to observe the basic principle of einclusion, and so, in our opinion and concerning Information Technologies (IT), universities should cooperate on a no-cost basis, by sharing e-services among them. This idea was at the inception of a proposal to the ALFA II program, entitled Remote Experimentation Network - yielding an inter-university peer-to-peer e-service (RexNet-yippee), which is described in some detail in the following section.

\section{The ALFA-II RexNet-yippee project}

\subsection{The network}

The ALFA-II program required networks to be composed of at least six Institutions of Higher Education (IHE): three from the European Union (EU) and three from Latin America (LA) - altogether from six different countries. As applications had to be accompanied by an original letter of intent from each IHE, stamped and signed by its legal representative (usually, the rector), there was a concern in gathering all elements for submitting the proposal in due time. To comply with these two requirements and establish a safety margin that would not compromise the deadline, we thought of setting up a consortium with at least one more IHE from a different country at both sides (EU \& LA) or at least one more IHE at each country ${ }^{2}$. We selected the last option because even if one single IHE from every country dropped out, this would not affect the geographical composition of the network, and therefore all the proposal contents could be readily adapted to reflect the present scenario, without compromising the role of a particular country ${ }^{3}$. Following the suggestion contained in the ALFA guidelines for applicants, the consortium also opted to separate the technical and scientific co-ordination (assigned to a Latin American IHE) from the financial execution (assigned to a European IHE, which is regarded as the legal coordinator by the European Commission). Therefore the consortium was formed by two balanced groups (EULA), each headed by an IHE with coordination duties.

2 It should be noticed that both options were feasible as, in our case, there was a large pool of IHE, from many different and eligible countries, willing to participate in the proposal.

3 In fact, we had a partner dropping out from the proposal only a couple of days before the deadline, because of problems in having the letter of intent signed in due time. 
- The Polytechnic Institute of Porto (Instituto Politécnico do Porto, IPP), Portugal - acting as the network coordinator.

- The University of Porto (Universidade do Porto, UP), Portugal.

- The University of Bremen (Universität Bremen, UB), Germany.

- The Technical University of Berlin (Technischen Universität Berlin, TUB), Germany.

- The University of Dundee (UD), Scotland.

- The Federal University of Santa Catarina (Universidade Federal de Santa Catarina, UFSC), Brazil - acting as the scientific coordinator.

- The Federal University of Rio Grande do Sul (Universidade Federal de Rio Grande do Sul, UFRGS), Brazil.

- The Catholic University of Chile (Pontificia Universidad Católica de Chile, PUCC), Chile.

- The Catholic University of Temuco (Universidad Católica de Temuco, UCT), Chile.

- The Institute of Technology and Higher Education of Monterrey (Instituto Tecnológico de Estudios Superiores de Monterrey, ITESM), Mexico.

\subsection{Goal(s)}

The project goals are: to share (1), harmonize (2), and spread (3) current skills on remote experimentation. First goal directly addresses the essence of the ALFA program, namely it calls for the cooperation among the consortium partners: those having already available a remote experiment (or lab) grant access to the all consortium, and those not having it will endure all efforts to set up at least one remote experiment useful to the consortium. Harmonization is a direct consequence of having universities from countries with different languages and cultures. Among other items it includes interface harmonization, with support to different languages, and curricula harmonization, i.e. defining a common set of practical experiments for a given course already served by a remote lab (or set of remote experiments). As the number of constituting partners of an ALFA network is restricted by budget constraints, each university participating in the RexNet project must act as a disseminating party within its own country, i.e. spread the access to remote experiments to other surrounding universities.

\subsection{Activities}

The activities leading to the implementation of each previously described goal (\#i) are:

- Create and maintain a web site for centring all the information relevant to the project, namely its objectives, the consortium partners, and the available remote experiments, among other items. The website should be accessible through an easyto-remember and comprehensive domain name - part of this activity has already been done by buying the domain http://www.rexlab.net (1).

- Kick-off meeting. The $1^{\text {st }}$ general meeting served as a starting point for the two following activities. Among the outcomes were the definition of a table with the first cross-institutional trials, with a clear indication of both the providing and client institutions, and the moment of realization (1).

- Specify and develop a common lab script structure for existing remote experiments $\left(1^{\text {st }}\right.$ iteration on $1^{\text {st }}$ year and $2^{\text {nd }}$ iteration on $2^{\text {nd }}$ year). Where possible, the lab script should contain editable fields, which may be filled in on-line. The system will be expected to return the indication of errors and suggestions of improvement, i.e. how the experiment should be repeated, preferably with tutor assistance (2).

- Identify and set up a pool of international (overseas) tutors for assisting on the conduction of remote experiments (the assistance will mainly be provided by audio or video-conference facilities, either integrated in the actual interfaces of the remote labs or as a separate resource) (1 and 2).

- $1^{\text {st }}$ round of cross-institutional trials with small target groups in the client institutions. The expected outcome is a full report covering aspects such as: ease of use; bandwidth requirements; quality of the lab scripts; among other items. This activity encompasses a series of short-term bilateral visits for 'breaking-the-ice' purposes - an aspect to be later addressed at this paper (1 and 2).

- Analysis of institutional needs within the areas covered by remote experiments supported by consortium members. The report should include the identification of courses offered by consortium members that could benefit from remote experiments made available within the consortium, and also address the harmonization of such courses, regarding the its practical contents (2).

- $\quad 2^{\text {nd }}$ round of cross-institutional trials in main stream classes. Expected outcome is a full report with a similar structure to the one resulting from the $1^{\text {st }}$ trials. A set of short-term bilateral visits is also included in this activity that should span over a period of six months to accommodate disciplines belonging to the $1^{\text {st }}$ or $2^{\text {nd }}$ semesters ( 2 and 3 ).

- International Workshops on Remote Experimentation (3).

\subsection{Past experience, current resources, and expected results}

Effective implementation of any activity done in cooperation is better achieved if the players understand and know well the role, past experience, current resources, and expectations of all involved. As the time distance between the proposal submission and the project start was longer than fifteen months, there was a 
need for updating such information, this being the objective of a small questionnaire distributed to all partners. The answers to the questions listed below were compiled by the coordinator and presented at the $1^{\text {st }}$ general consortium meeting to set up a common starting point.

1. List of e-courses provided / supported (specify name and type of learning environment used, e.g. Moodle, and provide link and access authorization, if needed). Specify if the educational materials are used within a traditional university degree or used as standalone courses.

2. List of remote experiments - provide link and access authorization, if needed. Specify in which context are experiments used.

3. Recent paper(s) describing your work on remote experimentation. Specify any other source of information you find suitable for describing your past work and current competences.

4. What do you expect to have within the next 6 months and 1 year?
Questions 1 and 2 directly address the partners' current resources on distance learning and remote experimentation. Question 3 provides a better insight of those resources while also enabling a brief idea on the evolution (past experience). Question 4 is intended to clarify the partners' expectations in the short-coming and longer future. Not being possible to present the four tables containing all the received answers (lack of space), we present in the next table those provided to question 1. A brief analysis reveals a very heterogeneous scenario within the consortium, namely: distance learning materials in different languages; proprietary, commercial, and open-source course management systems (CMS), or no CMS at all; etc. However, as three partners indicated a common, free, open-source CMS $[28,29]$, the consortium decided to:

- install the Moodle CMS at every partner's site.

- have one partner migrating a course on its proprietary CMS to Moodle and report results.

- have another partner migrating a course offered through a commercial CMS to Moodle and report results.

- indicate the creation of common logins for every Moodle CMS installed at the consortium members.

\section{Table 1. List of e-courses provided by the institutions involved in RexNet.}

\begin{tabular}{|c|c|}
\hline UFRGS & $\begin{array}{l}\text { We have some learn material on behaviour of open and close loop control systems using our remote laboratory with a } \\
\text { process control plant. All the material is in Portuguese. This material has been partially used in courses such as Signals } \\
\text { and Systems and Control Systems for electrical and computer engineering undergrad students. }\end{array}$ \\
\hline UFSC & $\begin{array}{l}\text { We have two e-modules: a) Introduction to Digital Systems; b) Introduction to Functional Programming. All the material } \\
\text { is in Portuguese. Other e-modules are being prepared, including one with UP on microcontrollers. This material has } \\
\text { been partially used in disciplines in Computer Science, Information Systems, and Electrical \& Computer Engineering. }\end{array}$ \\
\hline UCC & $\begin{array}{l}\text { We are starting to use a robotic simulation software for a Dynamics course and also a Robotics course. This software } \\
\text { was developed by myself as part of my ongoing research effort. My goal is to use this software as a virtual dynamics lab. } \\
\text { As part of this project I would like to attempt to link this software with a remote experiment, in order to evaluate the } \\
\text { potential of this approach for both research and teaching. }\end{array}$ \\
\hline UCT & $\begin{array}{l}\text { We are using our own environment (EDUCA: http://educa.uct.cl/), but we don't have any remote experiment yet. We } \\
\text { are recently working on it. }\end{array}$ \\
\hline ITESM & $\begin{array}{l}\text { Basic course in mobile robotics (optional for CS \& EE majors at the undergraduate level), basically about computational } \\
\text { aspects of mobile robots, including some basic knowledge on mechanics, sensors \& control. There is web material } \\
\text { supporting the course, including a simulated laboratory \& a tutor: http://dns1.mor.itesm.mx/ esucar/robotica.html. } \\
\text { During the course students make teams and build / program a small robot to participate in a competition. }\end{array}$ \\
\hline UB & $\begin{array}{l}\text { e-module "Introduction to mechatronics". The aim of this course-module is to provide students in technical training with } \\
\text { accompanying learning tasks, learning resources and communication facilities when using our mixed reality web service }\end{array}$ \\
\hline TUB & 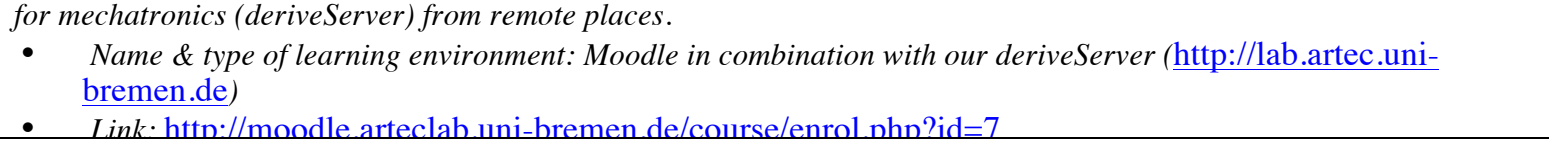 \\
\hline IPP & $\begin{array}{l}\text { No e-courses, as such, at the moment. However, interactive web resources, e.g. self-tests, are offered within a discipline } \\
\text { of Fundamentals of Electricity (Freshmen level, Electrical and Computer Engineering degree). }\end{array}$ \\
\hline UP & $\begin{array}{l}\text { We use Moodle, available at http://ptse.fe.up.pt/moodle/. This e-learning platform was installed and is being used in } \\
\text { the context of the MARVEL Leonardo da Vinci project. }\end{array}$ \\
\hline UD & $\begin{array}{l}\text { We used Blackboard as an eLearning platform, with use being required on all courses for students who enrolled in } 2004 . \\
\text { The University provides a variety of distance learning courses, also hosted on the Blackboard system. Blackboard is (in } \\
\text { principle) SCORM compliant. We have used both Click2Meet \& FlashCom as videconferencing platforms for eLearning. }\end{array}$ \\
\hline
\end{tabular}

Another concern was to link existing web-based materials to traditional courses offered by each partner, so that a cross-dissemination scheme could be drawn. This way, every partner was further requested to fill in two Excel files, each of which presented in table 2. The information enabled the consortium to identify possible links between $<$ institutions $><$ courses $><$ lecturers $>$ and $<$ institutions $><$ courses $><$ remote experiments $>$, ready to 
follow and explore within the $1^{\text {st }}$ project goal (share). An example of the information provided by one partner is presented in tables 3 and 4 .

Table 2. <Institution $><$ Lecturer $><$ Course $>$ and <Institution $><$ Remote Experiment $><$ Course $>$ tuples.

\begin{tabular}{|l|l|}
\hline Tuple \#1 & Tuple \#2 \\
\hline$<$ Institution $><$ URL $>$ & $<$ Institution $>$ \\
\hline$<$ School / Faculty $><$ URL $>$ & $<$ Remote Experiment $><$ URL $>$ \\
\hline$<$ Department $><$ URL $>$ & $<$ Goal (i.e. what is it good for $)>$ \\
\hline$<$ Degree $><$ URL $>$ & $<$ Requirements $>$ \\
\hline$<$ Lecturer $><$ URL $>$ & $<$ Lab script $><$ URL $>$ \\
\hline$<$ Course / Module $><$ URL $>$ & $<$ Course $/$ Module $>$ \\
\hline$<$ Year / Semester - Time $>$ & \\
\hline$<$ Classes from - till $>$ &
\end{tabular}

Table 3. An example of tuple \#1.

$<$ Universidade do Porto $><$ http://www.up.pt $>$

$<$ Faculdade de Engenharia $>$ <http://www.fe.up.pt $>$

$<$ Departamento Engenharia Electrotécnica e Computadores>

$<$ http://deec.fe.up.pt/>

$<$ Engenharia Electrotécnica e Computadores $>$

$<$ http://sifeup.fe.up.pt/si/disciplinas_geral.formview?p_c ad_codigo=EEC2104\&p_ano_lectivo $=2004 / 2005 \& p \_p e$ riodo $=1 \mathrm{~S}>$

<José M. Ferreira><http://www.fe.up.pt/ jmf>

$<$ Microprocessadores $><$ http://www.fe.up.pt/ jmf/mp $>$

$<2 \mathrm{Y} / 1 \mathrm{~S}-3 \mathrm{HT}+2 \mathrm{HP}>$

$<1^{\text {st }}$ week Oct. $-2^{\text {nd }}$ week Dec. $>$

Table 4. An example of tuple \#2.

$<$ Universidade do Porto $>$

$<2^{\text {nd }}$-order low-pass filter $><$ No URL - requires scheduling $>$

$<$ Teaching analogue electronics - basic concepts for active filters -

circuits based on operational amplifiers (opamps)>

$<$ Access through Moodle - Course "Introduction to electronics" - URL

- http://ptse.fe.up.pt/moodle/ - Use your login / password and

then schedule your time slot. Also requires a plug-in available from the page with the lab script - see URL at corresponding cell>

$<$ Language: English. Explains the experiment and the requirements

(plug-ins) - contains a link to video conference tools (based on

FlashCom) $><$ http://paginas.fe.up.pt/ jmf/rew/>

\section{$<$ Electronics $>$}

As illustrated by figure 1, possible inter-institutional matches between course(s) and remote experiment(s) are to be explored by each partner in the following manner:

- the contact person (lecturer) of one institution seeks for remote experiments useful for his/her course. If a match is found then contact the partner responsible for that remote experiment.

- the contact person of one institution seeks for courses - offered by his/her institution - that could benefit from a remote experiment made available by the contact person of a partner institution. If a match is found then contact the colleague responsible for that course and if he/she evidences interest then mediate the establishment of a link.

- the contact person of one institution seeks for remote experiments - supported by his/her institution - that could serve a course lectured by the contact person of a partner institution. If a match is found then contact the colleague responsible for that remote experiment and if he/she shows interest to make it available then mediate the establishment of a link.

A central point in this approach is that any interinstitutional link must be established through the social involvement of at least one project partner. This is a key aspect in our vision of a peer-to-peer network, i.e. we empower each partner that must act as a social linker between provider(s) and client(s), while he/she can also accumulate one of these two roles (client / provider).

\section{Figure 1. Establishing inter-institutional links between courses and remote experiments.}

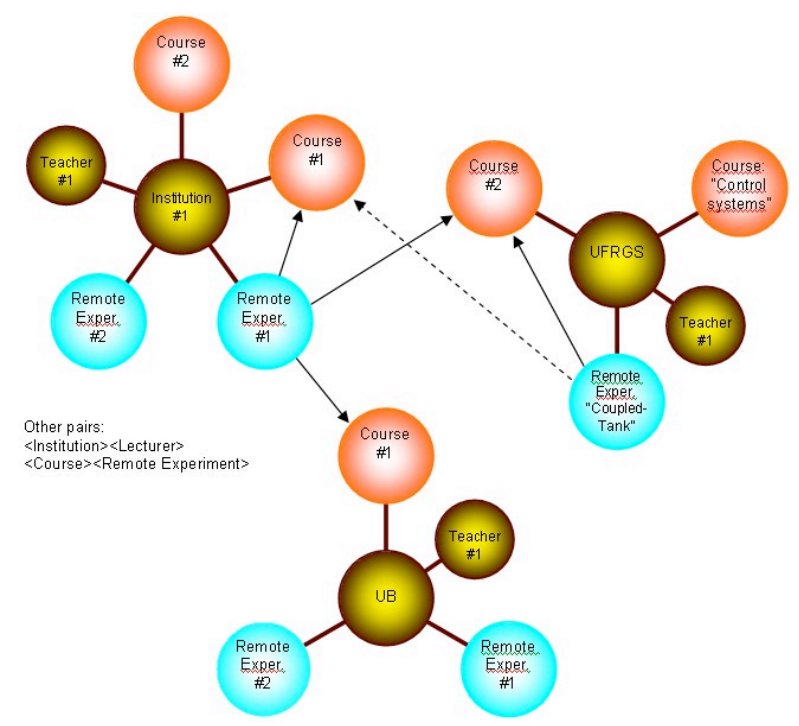

\section{Benefits \& challenges of a peer-to- peer network in Remote Experimentation}

In our view, the social involvement of at least one player highly motivated to and deeply involved in remote experimentation, is a key aspect for guaranteeing the success of such a peer-to-peer network. It is precisely the human (or social) factor that ultimately makes the difference - if users know that the system is open to a large community where the chance of interacting with people from other countries (and cultures) is high, while also knowing that there is a common basis for understanding, namely the subjects addressed by the practical work associated with a given remote experiment, then motivation increases and the level of scepticism towards a remote approach (in direct comparison to using a real lab) decreases. The 
combination of these two factors (higher motivation, lower scepticism) undoubtedly increases the educational value of remote experimentation, namely if users are able to practice their social skills while cooperating to achieve a certain learning objective. The passage to such a scenario comes from the underlying social relations already established through the RexNet project - among the providers of remote experiments and the contact persons of the potential client institutions, who are responsible for mediating the all process, i.e. seeking for potential users within their own institutions, explaining the benefits of remote experimentation, initiating the dialogue between client and provider and then carefully following the established connection for any possible troubleshooting. Besides this social intervention, all partners are encouraged to promote the development of new remote experiments addressing real needs identified within the consortium - a concerted effort that brings in additional benefits:

- the initial quantity of potential users is multiplied by the number of institutions belonging to the network.

- reduces the effort to set up remote experiments, especially if using free and/or open-source tools already in use within the consortium (e.g. CMS, synchronous communication tools, among others).

This last aspect - use of free and/or open-source tools - is well illustrated in figure 2 , which shows an audio conference with five RexNet partners, using Skype [30] - a free, peer-to-peer, web-based audio conference tool. Some partners of the RexNet consortium have been using and evaluating many different synchronous communications tools ${ }^{4}$ for the past years [e.g. 31, 32], and to their best knowledge the present solution provides a good quality level, recently verified through an intercontinental audio conference session with three EU partners (from Portugal and Germany) and two LA partners (from Brazil and Mexico).

\section{Figure 2. An EU-LA audio conference session with a moderator plus four participants.}

4 Essential for setting up a collaborative environment in a remote lab

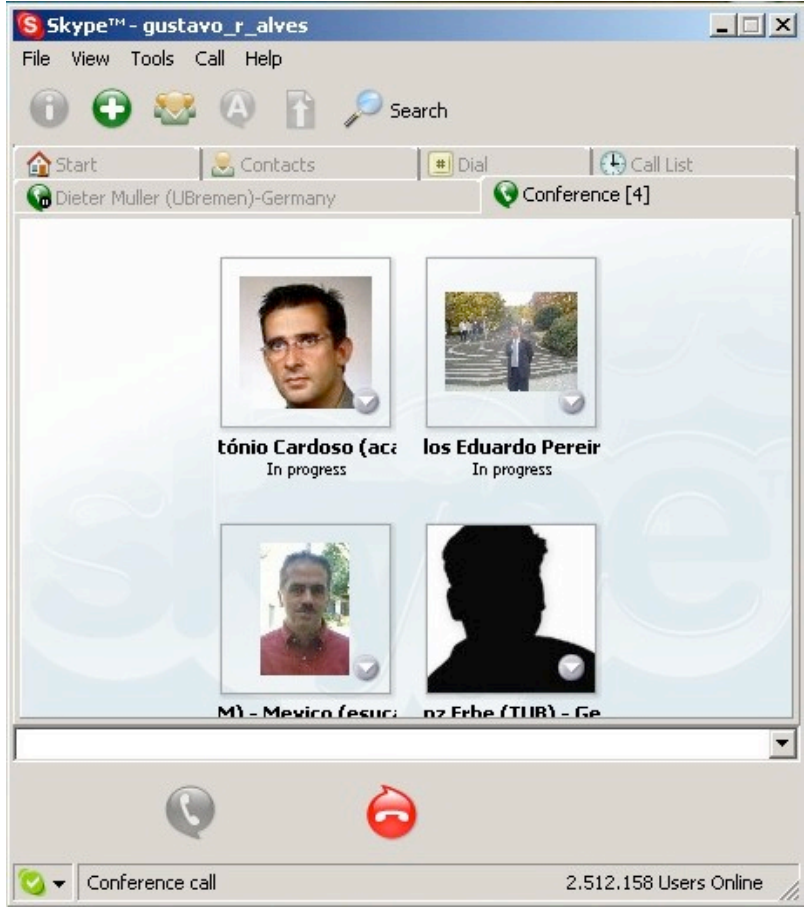

The academic, non-commercial nature of RexNet also enables the association with similar networks, such as PROLEARN (a 'Network of Excellence' financed by the Information Society Technology programme of the European Commission), which deals with technology enhanced professional learning and (via workpackage 3 in particular) online experimentation [33]. At this point in time, contacts have already been initiated and the process of establishing a partnership in underway.

Besides the benefits pointed out, there are several challenges associated with a peer-to-peer network of remote labs, namely:

- The effort required to harmonize the interface to each remote experiment (or lab), namely of those already available $[34,35,36,37$, and 38]. Considering the additional requirement of multilingual support, such effort considerably increases.

- Increasing the number of potential users also increases the potential demand for tutor assistance. Even if the number and availability of tutors is reinforced by setting-up an international tutors' pool - taking advantage of the different time zones, e.g. time distance between Germany and Mexico is 7 hours - pertinent questions like the language and the level of demand will always arise.

- Additional costs associated with the short-term bilateral visit between the remote experiment provider and the institutional client, which should precede every newly established link. Although one could argue that 'breaking-the-ice' is also possible through video or audio-conference, the advantages of presential, face-to-face first acquaintances are generally well understood and accepted by all. 


\section{Conclusion}

To conclude, we believe that in addition to the listed benefits and challenges associated with a peer-to-peer network of remote labs, it is possible others to exist or arise, depending on the type of remote lab in question or on the natural technological advances that often solve old problems and always create new ones.

\section{Acknowledgements}

The authors acknowledge the sponsorship of the European Commission, EuropeAid, Cooperation Office, through Project ALFA-II-465-A.

\section{References}

[1] Goertz, R., and Thompson, R., "Electronically controlled manipulator," Nucleonics, 1954.

[2] Ferrell, W.R., Sheridan, T.B., "Supervisory Control of Remote Manipulation," IEEE Spectrum, vol. 4, 1967, pp. 81-88.

[3] Goldberg, Ken, Mascha, Michael, Gentner, Steve, Rothenberg, Nick, Sutter, Carl, and Wiegley, Jeff, "Desktop Teleoperation via the World Wide Web", Proceedings of the IEEE International Conference on Robotics and Automation, 1995, pp. 654-659.

[4] Gertz, M., Stewart, D., et al., "A Human-Machine Interface for Distributed Virtual Laboratories", IEEE Robotics \& Automation Magazine, December 1994.

[5] Cobby, M., Nicol, D., Durrani, T. S., Sandham, W. A., "Teaching Electronic Engineering Via the World Wide Web", Proceedings of the IEE Colloquium on Computer Based Learning in Electronic Education, 1995, pp. 7/17/11.

[6] Richards, P., "MIT to make nearly all course materials available free on the WWW", 2001, http://web.mit.edu/newsoffice/nr/2001/ocw.html.

[7] Aktan, B., Bohus, C. A., Crowl, L. A. and Shor, M. H., "Distance Learning Applied to Control Engineering Laboratories", IEEE Transactions on Education, Vol. 39, n. 3, August 1996, pp. 320-326.

[8] Esche, S. K., "On the Integration of Remote Experimentation into Undergraduate Laboratories Technical Implementation", submitted to International Journal of Instructional Media, 2005.

[9] Esche, S. K., "On the Integration of Remote Experimentation into Undergraduate Laboratories Pedagogical Implementation", submitted to International Journal of Instructional Media, 2005.

[10] Zeilmann, R., Gomes Jr., J.M., Bazanella, A., and Pereira, C. E. "Web-based Control Experiments on a Foundation Fieldbus Plant", $5^{\text {th }}$ IFAC International Conference on Fieldbus Systems and their Applications, Aveiro, Portugal, July 2003, pp. 325-330.

[11] INSIGHT II,

1997,
[12] ASTEP, 1999, http://www.cee.hw.ac.uk/ astep/.

[13] Ferreira, J., MacKinnon, L., Desmulliez, M., and Foulk, P., "A Multimedia Telematics Network for On-the-Job Training, Tutoring and Assessment," Proceedings of the International Conference on Engineering Education (ICEE'98), Rio de Janeiro, Brazil, August 1998.

[14] Foulk, P., Desmulliez, M., MacKinnon, L., and Ferreira, J., "The ASTEP Educational Multimedia Framework," Proceedings of the $2^{\text {nd }}$ European Workshop on Microelectronics Education (EWME'98), Enschede, Netherlands, May 1998, pp. 213-216.

[15] ALLEGRO, 2000, http://www.fe.up.pt/ allegro.

[16] PEARL, 2001, http://iet.open.ac.uk/pearl/.

[17] Fidalgo, André V., Costa, R. J., Ferreira, J. M., and Alves, G. R., "Experimenting the 1149.1 and 1149.4 test infrastructures in a Web-accessible remote Lab (without Plug-ins!)", Proceedings of the $16^{\text {th }}$ Conference on Design of Circuits and Integrated Systems, Porto, Portugal, November 2001.

[18] Ferreira, J. M., Alves, G. R., Costa, R. J., and Hine, N., "Cooperative learning in a web-connected workbench", Lecture Notes on Computer Science 2438, "Groupware: Design, Implementation and Use", ISBN 3-540-44112-3, Springer, Proceedings of the $8^{\text {th }}$ International Workshop on Groupware, La Serena, Chile, 2002.

[19] Cooper, M., Donnelly, A., and Ferreira, J. M., "Remote controlled experiments for teaching over the Internet: A comparison of approaches developed in the PEARL project", Proceedings of the $19^{\text {th }}$ annual conference of the Australian Society of Computers In Learning In Tertiary Education, Auckland, New Zealand, 2002

[20] Alves, G. R., Cardoso, A., and Ferreira, J. M., "Remote Electronics Workbench - Taking the Lab Home", Invited session on Remote Experiments for e-learning (Virtual Laboratories) within the $11^{\text {th }}$ IFAC Symposium on Information Control Problems in Manufacturing, Salvador da Bahia, Brazil, April 2004.

[21] Cyberlab - The Experiment Service Provider, http://www.cyberlab.org/, 2005.

[22] MIT iLab Service Broker, http://ilab.mit.edu/, 2005.

[23] Eikaas, T. I., Schmid, C., Foss, B. A., and Gillet, D. "A Global Remote Laboratory Experimentation Network and the Experiment Service Provider Business Model", Conference on e-Work and e-Commerce (e2002), Prague, Czech Republic, 2002.

[24] Chang, V., and del Alamo, J. A., "Collaborative WebLab: Enabling Collaboration in an Online Laboratory", Proceedings of World Congress on Networked Learning in a Global Environment, Berlin, Germany, May 2002.

[25] Callaghan, M. J., Harkin, J., Peters, C., McGinnity, T.M., and Maguire, L. P., "A Collaborative Environment for Remote Experimentation", Proceedings of the International Conference on Microelectronic Systems Education, Anaheim, California, USA, 2003

[26] Erbe, H-H., and Bruns, F. W., "Didactical Aspects of Mechatronics Education", Proceedings of the $5^{\text {th }}$ IFAC 
International Symposium on Intelligent Components and Instruments for Control Applications, Aveiro, Portugal, 2003.

[27] Faltin, N., Böhne, A., Tuttas, J., and Wagner, B., "Distributed Team Learning in an Internet-Assisted Laboratory", International Conference on Engineering Education, Manchester, U.K., August 18-21, 2002.

[28] Landon, B., "On-Line Educational Delivery Applications: A Web Tool for Comparative Analysis", http://www.edutools.info/index.jsp, 2003.

[29] Moodle, http://moodle.org/, 2005.

[30] Macromedia, Flash Communication Server, http://www.macromedia.com/software/flashcom/, 2005

[31] CUSeeMe QuickNet. In: http://www.cuseeme.com, 2003
[32] Macromedia, Flash Communication Server, http://www.macromedia.com/software/flashcom/, 2005

[33] PROLEARN, http://www.prolearn-project.org, 2005.

[34] Remote Experimentation Laboratory (RexLab), http://rexlab.ufsc.br/, 2005.

[35] Remote Electronics Workbench, http://www.fe.up.pt/ jmf/rew, 2005.

[36] Remote lab on robotics, automation and control, http://automation.eletro.ufrgs.br/planta/, 2005.

[37] Lab@future - a mixed reality web service for Mechatronics, http://lab.artec.uni-bremen.de/, 2005.

[38] Laboratorio Virtual de Robótica Móvil, http://doc.mor.itesm.mx:8181/robot/, 2005. 